\title{
Children affected by severe drought in a rural community in the central highlands of Sri Lanka
}

\author{
Manouri P Senanayake ${ }^{1}$, M D C J P Jayamanna ${ }^{2}$ \\ Sri Lanka Journal of Child Health, 2014; 43(1): 23-26
}

\begin{abstract}
Introduction: Children are particularly vulnerable to climate change. This case study describes effects of shortages in irrigation and drinking water on children of a rural village in Sri Lanka.
\end{abstract}

Objective: To assess children's health and describe the coping strategies at family and community level in a village seriously challenged by water shortage.

Method: A community-based cross-sectional study was carried out in Serupitiya, a village in the eastern slopes of Nuwara Eliya district identified in 2012 as one of the worst drought affected communities in Sri Lanka. After a six month period of drought, data was gathered using an interviewer administered questionnaire from 68 households (out of total 207) selected by systematic random sampling. Children $<12$ years underwent medical examination and nutritional assessment. Focus group discussions identified practices and adaptations to water shortage at community level.

Results: In the 68 households 98 children were $<12$ years with a male: female ratio of $1: 1$. Of the 98 children, $49 \%$ were $5-12$ years, $42 \% 1-5$ years and $9 \%$ infants. Entire population faced severe economic hardships. Parental education was only up to primary school. There were frequent respiratory infections and dust-related cough in $63 \%$, "recurrent fever" in $69 \%$, dermatological complaints in $21 \%$ and diarrhoeal illness in $21 \%$. There were no dengue infections and no increase in vector borne diseases. There was no mortality among infants or under-fives. Disturbed nights with "not settling at night" occurred in $80 \%$, "waking for water to quench thirst" in $40 \%$ and "due to discomfort of room temperature" in $40 \%$. Increased household stress levels caused irritability, apathy, short tempers and increased quarrels among

\footnotetext{
${ }^{1}$ Senior Professor in Paediatrics, ${ }^{2}$ Research Assistant, Department of Paediatrics, Faculty of Medicine, Colombo
}

(Received on 27 May 2013: Accepted after revision on $26^{\text {th }}$ July 2013) adults in over $80 \%$ of families. Development was age appropriate in 95\%; schooling was uninterrupted and drop-out rate $<12$ years was zero. Severe acute malnutrition was present in $12 \%$ of $5-12$ year olds and $5 \%$ of $1-5$ year olds. There was a statistically significant increase of malnutrition with age $(\mathrm{p}<0.05)$.

Conclusions: Main child health issues were protein energy malnutrition (PEM), skin sepsis, poor oral hygiene, respiratory symptoms and disturbed sleep at night. School aged children had significantly more severe acute PEM than preschoolers. Preventive health care strategies provided to 0 - 5 year olds had effectively prevented PEM and micronutrient deficiency in under-fives.

(Key words: water shortage; child health; climate change)

\section{Introduction}

Children are the first to be affected by any change to the physical environment. Depletion of water resources due to global warming and its effects on child health is a topic to which attention of paediatricians has been drawn ${ }^{1-4}$. Sri Lanka is not spared from global warming. Problems of drought affected communities in the 'dry zones' of the country have worsened due to reduction in seasonal rainfall and rising temperature. We report on the health of children of a rural community seriously challenged by water shortage, resulting from changed rainfall patterns.

\section{Objective}

To assess children's health and to describe the coping strategies to water shortage at family and community level

\section{Study setting}

Serupitiya, a village in the eastern slopes of Nuwara Eliya district

\section{Study sample}

Sixty eight randomly selected households 


\section{Method}

A community-based cross-sectional study was carried out in this village identified in 2012 by the Global Environment Facility of the United Nations Development Program (UNDP) as one of the worst drought affected communities in Sri Lanka. Of a total of 207 households, a sample of 68 was selected using systematic sampling (every third house) for field visits after an unbroken drought of six months. Households without a child below 12 years or unwilling/unavailable to participate were excluded, and the next household included.

A house to house survey using an interviewer administered questionnaire gathered information from the chief occupant or spouse on socio-economic details and problems faced due to water shortage at individual or household level. All children between the ages of 2 months to 12 years underwent a complete medical examination including height and weight measurements, assessment for nutritional deficiency, physical examination and screening for developmental and behavioural problems. Practices and adaptations to the on-going water shortage, at community level were identified by interviewing key stakeholders and conducting focus group discussions with persons of all age groups.

\section{Results}

The 68 households had 170 children $<18$ years. There were 98 children $<12$ years with a male: female ratio of 1:1. They comprised 48 (49\%) 5-12 year olds, 41 (42\%) 1-5 year olds and $9(9 \%)$ infants. Tables $1 \& 2$ show the demographic details and morbidity patterns.

\section{Table 1}

Demographic details \& socioeconomic profile of residents of Serupitiya

Total no. of households

Total males (all ages)

Total females ( all ages)

620

No. with physical disabilities

23

No. on long term medications $\quad 50+$

Monthly income

Variable, not specifiable,

Sources of income

Vegetable farming, unskilled labour

Work in rice fields, dairy farming

Monthly expenditure per household < Rs 8000

No. possessing savings accounts

No. of families receiving Samurdhi benefit 127
Table 2

Morbidity pattern during drought period $(n=98)$

\begin{tabular}{lc} 
Recurring fever & $68(69 \%)$ \\
Respiratory infection & $62(63 \%)$ \\
Diarrhoeal illnesses & $20(21 \%)$ \\
Skin infections & $20(21 \%)$ \\
Dental caries & $32(33 \%)$ \\
Severe/moderate acute malnutrition & $16(16 \%)$ \\
\multicolumn{1}{c}{$\begin{array}{l}\text { 1-5 years } 5-12 \text { years } \quad 12(24 \%) \\
\text { Dengue infections }\end{array}$} \\
No. not immunized up to date & 0
\end{tabular}

Frequent respiratory infections and dust-related cough in $62(63 \%)$, "recurrent fever" in $68(69 \%)$ and dermatological complaints were conditions that increased the need for seeking medical attention for children $<12$ years during the dry season. Frequency of diarrhoea had "not increased" and a diarrhoeal illness was reported in $20(21 \%)$ children within the past six months, two of whom had needed intravenous fluids for correction of dehydration when taken to hospital. There had been no dengue infection nor any increase in vector borne diseases. There was no mortality among infants or under-fives.

Disturbed night sleep was a prominent complaint. "Not settling at night" (80\%) was attributed to "waking for water to quench thirst" (4\%) and "discomfort of high temperature" (40\%). Increased household stress levels due to lack of sleep was apparent and over $80 \%$ of families complained of, irritability, apathy, short tempers and increase in arguments/fights among adults. No cases of child abuse were mentioned.

Age appropriate development was found in 93 (95\%); and delayed development in 5\%. Schooling was largely uninterrupted. School drop-out rate was zero and no child $<12$ years had become a wage earner. Older children trekked 2-3 kilometers to the stream for bathing and washing purposes, often more than once a day and helped the family in water related activities.

Physical examination found severe acute malnutrition (weight/height $\leq 3 \mathrm{SD}$ in $1-5$ year olds and body mass index (BMI) $\leq 2 \mathrm{SD}$ in $5-12$ years) in 6 (12\%) 5-12 year olds and $2(5 \%) 1-5$ year olds. Another $6(12 \%)$ and $2(2 \%)$ of the two age groups had moderate acute malnutrition. There was a statistically significant increase of malnutrition with age $(\mathrm{p}<0.05)$. No child had features of kwashiorkor or marasmus and one was overweight. Clinical features of micronutrient deficiency were not found apart from mild-moderate 
pallor in $2(2 \%)$ children. There were no Bitot spots detected in 98 children examined. Depigmented hair was present in eight children of whom six were above five years. Majority of children had poor personal hygiene, head lice and dental caries was present in 32 (33\%). Miliaria ("prickly heat rash") with secondary bacterial infection or impetigo was present in 20 $(21 \%)$.

All three babies born during the drought were exclusively breast fed with adequate weight gain. Immunization was up-to-date in $85 \%$ of children and the public health midwife visited the homes regularly. Dietary practices and consumption patterns found that only one rice meal was cooked at night, left-overs being consumed in the morning too. Animal proteins were limited to dried fish rarely. There was little food diversity. 'Kalu-kamberiya' (Solanum nigrum) a herb growing wild in the surrounding wild life sanctuary, believed to contain medicinal properties, was consumed at all meals.

A community water scheme supplied water for drinking along a one inch in diameter pipeline and was restricted to one hour per day or sometimes every other day. Drinking water was stored in plastic containers in every home but for all other purposes (washing, bathing, sanitation) a stream, 45-60 minute walk away, served as the water source. Lack of irrigation created serious economic problems to this vegetable farming community and $70 \%$ of the families fell within limits of eligibility for Samurdhi, the government benefit scheme meant for the poorest segment of society. Many men left the village in search of alternate incomes. UNDP introduced livestock farming had markedly improved earning capacity and further development of local dairy farming was underway.

\section{Discussion}

Serupitiya is a village nestled in the highlands of Sri Lanka. Although lying within the catchment area for a hydro-electric water reservoir (Randenigala) in the central hills of the country, difficulties in water access were caused by its high elevation, steeply sloping land structure and strong winds drying the surface water. Due to children being affected in a variety of ways in such conditions, we focused not only on their health but also on the social aspects of the entire family.

The main child health issues we found were protein energy malnutrition (PEM), skin sepsis, poor oral hygiene and respiratory symptoms. The latter was possibly dust related. PEM was more severe in the school age population that in the preschool age group.

Preventive health care strategies of regular home visits by the public health midwife, practice of exclusive breast feeding and regular growth monitoring accounted for the good nutritional status in infants and preschool children. Six monthly vitamin A supplementation to children aged 6-60 months and the Thriposha food supplementation program accounted for the lack of vitamin A and other micronutrient deficiencies.

With regard to impact on child development, although schooling was uninterrupted we found that older children were trekking 45 minutes or more each way for water on a daily basis after returning from school, restricting social activities and leaving little time for play. Family cohesion and harmony were also affected.

Climate induced hardships were familiar to this community but in recent years prolonged drought had worsened both drinking and irrigation water shortages, to a scale not previously encountered. Outward migration of adult males in search of employment added to the difficult tasks the left behind children and females had to undertake for survival. There was active community participation towards locally managing the water scheme.

Climate change and its impact on children has not been adequately investigated. This case study found the age group affected by severe PEM to be different from the age group thus affected according to national statistics. Findings in a single waterchallenged community are inadequate to draw conclusions on the relationship between climate induced water shortage and child health. In view of the fact that further climate change is likely, we propose that research focused on children of affected communities be conducted, for appropriate preventive action to be taken.

\section{Acknowledgements}

We thank Mrs. Sherine Samarasooriya and Mrs. Dinali Jayasinghe both of UNDP Sri Lanka and the Global Environmental Facility of UNDP for facilitating this study, Ms. Renuka Badrakanthi of Women's Development Federation Waligapola for her invaluable help and all those who assisted us during the field visits. 


\section{References}

1. Bunyavanich $\mathrm{S}$, Landrigan $\mathrm{CP}$, McMichael AJ, Epstein PR. Impact of climate change on child health Ambulatory Paediatrics 2003; 3:44-52.

2. Shea KM. Global climate change and children's health. Pediatrics 2007; 120:1149-52.

http://dx.doi.org/10.1542/peds.2007-2646

3. Waterston T, Lenton S. Sustainable development, human induced global climate change and the health of children. Archives of Disease in Childhood 2000; 82:95-7.

http://dx.doi.org/10.1136/adc.82.2.95
4. Kistin EJ, Fogarty J, Pokrasso RS, McCally M, McCornick PG. Climate change, water resources and child health Archives of Disease in Childhood 2010;95:545-9.

http://dx.doi.org/10.1136/adc.2009.175307

5. Galiani S, Gertler P, Schargrodsky E. Water for life: The impact of the privatization of water services on child mortality. Journal of Political Economy 2005;113:83-120

http://dx.doi.org/10.1086/426041 